\title{
SCIENTIFIC REPORTS
}

natureresearch

Check for updates

\section{Enhanced mechanical and wear} properties of Al6061 alloy nanocomposite reinforced by CNT-template-grown core-shell CNT/SiC nanotubes

\author{
Sung Chan Yoo ${ }^{1,3,4}$, Byungchul Kang ${ }^{1,4}$, Pham Van Trinh ${ }^{2}$, Doan Dinh Phuong² \& \\ Soon Hyung Hong ${ }^{1 \bowtie}$
}

Novel one-dimensional template-grown coaxial SiC@carbon nanotubes (SiC@CNTs) were fabricated using a chemical vapor deposition method. To facilitate the formation of SiC on CNT template, a molecular-level mixing process was used to coat the surface of commercial multiwalled carbon nanotubes (MWCNTs) by $\mathrm{Fe}_{2} \mathrm{O}_{3}$. These Fe-CNTs were transformed into SiC@CNT nanotubes, which were then mixed with Al6061 alloy and consolidated by spark plasma sintering to obtain Al6061-SiC@ CNT nanocomposites. The addition of 5 vol\% SiC@CNT resulted in $58 \%$ enhancement in Young's modulus and $46 \%$ enhancement in yield strength. Furthermore, the friction coefficient was reduced by $31 \%$ and the specific wear rate was reduced by $45 \%$. The enhancement effect of Al6061-SiC@CNT on the mechanical and tribological properties was much greater than those of traditional nanoparticles, nanowires, and whiskers of SiCs. The extraordinary strengthening behavior of SiC@CNT, when compared with that of other $\mathrm{SiC}$ analogues, is attributed to the coaxial structure consisting of a $\mathrm{SiC}$ shell and CNT core. This coaxial structure enhanced the mechanical and tribological properties beyond that attainable with traditional SiC-derived reinforcements.

Metal-matrix composites (MMCs) are increasingly being used in aerospace and automobile industries due to their excellent properties, such as elastic modulus, hardness, tensile strength, and wear resistance ${ }^{1,2}$. Commonly used metallic matrices include $\mathrm{Al}, \mathrm{Mg}$, $\mathrm{Ti}$, and their alloys. Generally, alloys are the preferred matrix materials for MMCs, due to possibilities to additional strengthening effects and flexible property design. For MMCs, fibers, whiskers, and particulates are commonly used as reinforcements ${ }^{2,3}$. Amongst the alloy systems, Al6061 alloy is a popular choice as a matrix material, due to their high corrosion resistance and strength, which enables the material to be used in various structural applications, including automotive, construction, and marine engineering ${ }^{4}$. The various properties of these alloys can be further enhanced by the addition of reinforcement materials, such as alumina $\left(\mathrm{Al}_{2} \mathrm{O}_{3}\right)$ and silicon carbide $(\mathrm{SiC})$, which has led to the development of highly strong metal matrix composite materials with tailorable properties for specific applications. Among the ceramic reinforcements, $\mathrm{SiC}$ has been the most widely investigated ${ }^{5-8}$. $\mathrm{SiC}$ has excellent properties including high electron mobility, high thermal conductivity, high tolerance for electrical breakdown, high hardness, and high mechanical strength . Many researchers have reported enhanced mechanical and wear properties of Al6061 alloys reinforced with $\mathrm{SiCs}^{10-15}$. For example, Kumar et al. ${ }^{12}$ reported fabrication of $\mathrm{SiC}$ particle reinforced Al6061 alloy composites by liquid metallurgy route via stir casting technique. In the present study, the authors suggest that the addition of $\mathrm{SiC}$ particles have significantly enhanced both mechanical and wear properties of the resulting composites. Yu

\footnotetext{
${ }^{1}$ Department of Material Science and Engineering, Korea Advanced Institute of Science and Technology, 291 Daehak-ro, Yuseong-gu, Daejeon 305-701, Korea. ${ }^{2}$ Institute of Materials Science, Vietnam Academy of Science and Technology, 18 Hoang Quoc Viet Str., Cau Giay Distr., Hanoi, Viet Nam. ${ }^{3}$ Korea Atomic Energy Research Institute, 111 Daedeok-daero 989 Beon-gil, Yuseong, Daejeon 34057, Korea. ${ }^{4}$ These authors contributed equally: Sung Chan Yoo and Byungchul Kang. ${ }^{\boxplus}$ email: shhong@kaist.ac.kr
} 
(a)

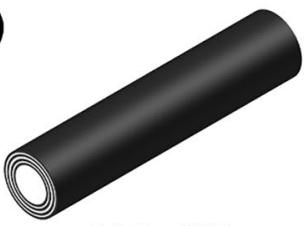

Pristine CNT (b)

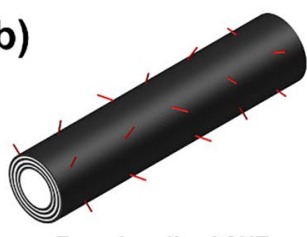

Functionalized CNT (c)

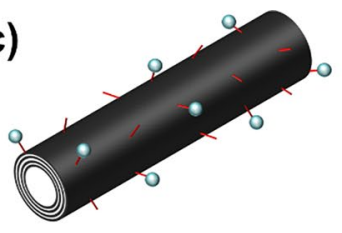

Fe-coated (Activated) CNT (d)

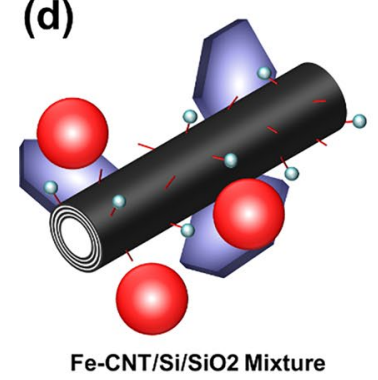

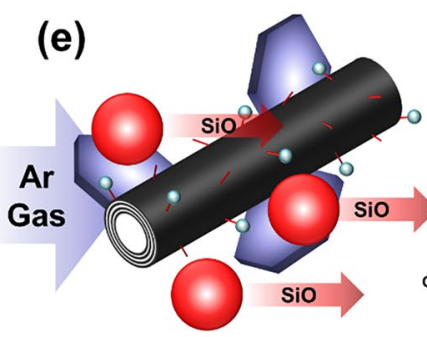

Ar gas-induced

CNT-template $\mathrm{SiC}$ growing Process (f)

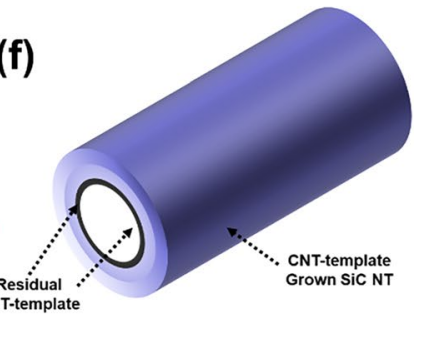

CNT-templated SiC Nanotube

Figure 1. Schematic illustration of the fabrication of the CNT-templated $\mathrm{SiC}$ nanotubes. (a) Pristine CNT, (b) functionalized CNT, (c) Fe-coated CNT, (d) Fe-CNT/Si/SiO 2 powder mixture, (e) Ar gas-induced CNTtemplate growing process of $\mathrm{SiC}$, and (f) CNT-templated SiC nanotube (SiC@CNT).

et al. ${ }^{16}$ demonstrated the effects of applied load and temperature on the dry sliding wear behavior of Al6061$\mathrm{SiC}$ composites. Liang et al. ${ }^{17}$ reported that MMCs containing $\mathrm{SiC}$ particulates had improved wear resistance.

Recently, with improved understanding of the strengthening behavior of reinforcements and the development of nanomaterials, extensive research effort has been devoted to the design and synthesis of SiCs with different dimensionalities ${ }^{18,19}$. For example, one-dimensional (1D) nanostructure of SiCs have higher aspect ratios and provide greater strengthening effect than traditional zero-dimensional structures. Moreover, additional modifications in the nanoarchitecture of 1D nanotube can be accompanied to form a 1D heterostructure, such as core-shell structure, which can offer greater possibilities of enhancing functionality that was not achievable with the single-component counterparts ${ }^{20}$. Coaxial nanotubes can be fabricated by depositing a secondary phase material over the surface of nanotubes ${ }^{21,22}$. The resulting heterostructured nanotubes can maintain the 1D features of template nanotubes in the axial direction. Amongst the possible choice of template materials, CNTs have been considered as ideal templates to grow 1D nanostructures, due to their structural and morphological integrity ${ }^{23}$. CNT templates can spatially confine the reactions; therefore the nanotubes grown from the CNT templates can have diameters, lengths, and orientations close to those of $\mathrm{CNTs}^{17}$. Hence, great effort has been devoted to the direct synthesis of special 1D coaxial nanotubes using CNTs as the template ${ }^{24-26}$. Nevertheless, the effect of CNT-template grown coaxial SiC@CNT nanotubes on various properties, such as mechanical and wear properties, has not been realized in the field of MMCs.

Carbothermal reduction of silica is the most useful method of SiC nanowire synthesis because of its efficiency and simplicity. Herein, $\mathrm{SiC}$-based nanotubes were prepared by forming an outer layer of $\mathrm{SiC}$ on the surface of the CNT template via direct reaction between CNTs and silica.SiC@CNT coaxial nanotubes were fabricated on a $\mathrm{Fe}_{2} \mathrm{O}_{3}$-catalyzed $\mathrm{Si}$ substrate via carbothermal chemical vapor deposition (CVD). The SiC@CNT nanotubes were mixed with Al6061 alloy and consolidated by spark plasma sintering (SPS) to form SiC@CNT-reinforced Al6061 (Al6061-SiC@CNT) composites. The mechanical and wear properties of these nanocomposites were characterized.

\section{Results and discussion}

Fabrication of CNT-templated SiC (SiC@CNT) and SiC@CNT/AI6061 nanocomposites. The fabrication process of the CNT-templated SiC nanotube-reinforced Al6061 nanocomposites involved six stages, starting with functionalization of CNTs and ending with consolidation to obtain a nanocomposite material. Figure 1 schematically illustrates the fabrication process. First, commercially available MWCNTs were functionalized using a standard acid treatment (Fig. 1b) ${ }^{27}$. This acid treatment resulted in defect functionalization of the CNT surface, forming chemical functional groups including hydroxyl, carboxyl, and epoxide groups. The evolution of functional groups on the surface of CNTs enables the dispersion of MWCNTs in polar solvents, such as water, and also the attachment of positively charged metallic ions when they are present in the solution. Because the functional groups on CNTs are negatively charged ${ }^{28}$, positively charged metallic ions can interact with functional groups through electrostatic forces. When metallic salts are dissolved in water, the positively charged metallic ions are released. These ions can electrostatically interact with negatively charged functional groups on CNTs, resulting in nucleation of Fe oxides on the surface of the CNTs. Similar water-based nucleation process has been discussed in our previous works on the molecular-level mixing process ${ }^{29-31}$.

During experiments, decorated Fe nanoparticles on the surface of CNTs acted as a catalyst for the SiC forming reaction ${ }^{32-34}$. When $\mathrm{Fe}-\mathrm{CNT}$ and $\mathrm{SiO}_{2}$ were mixed together, the flow of inert gas within the furnace mediated the 

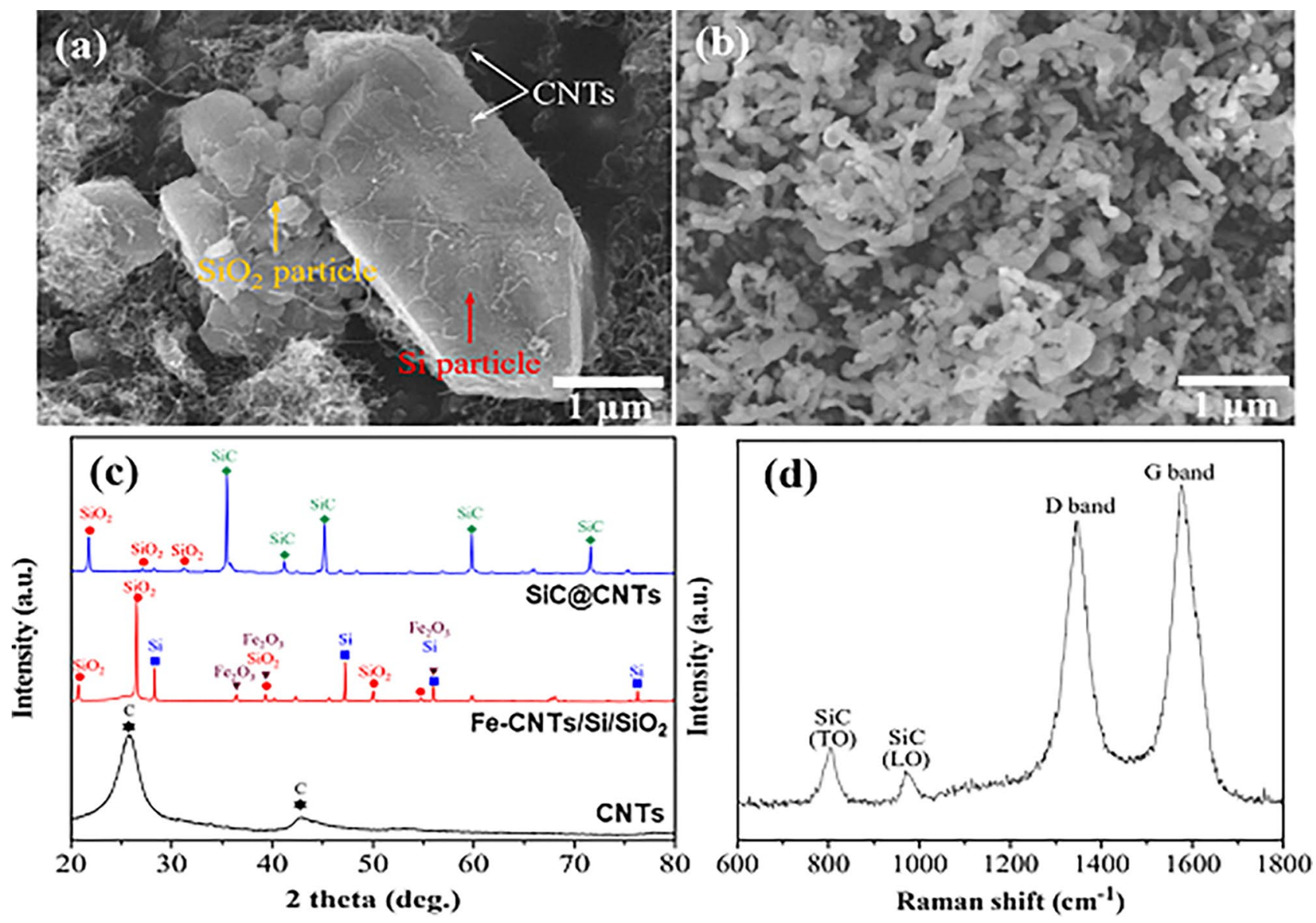

Figure 2. (a) Microstructure of the $\mathrm{Fe}-\mathrm{CNT} / \mathrm{Si} / \mathrm{SiO}_{2}$ powder mixture. (b) Microstructure of the CNT-templated $\mathrm{SiC}$ nanotubes (SiC@CNTs), (c) X-Ray diffraction patterns during the fabrication process, and (d) Raman spectra.

flow of metastable $\mathrm{SiO}$ gas from the $\mathrm{SiO}_{2}$. During the heat treatment process, this $\mathrm{SiO}$ gas contacted liquid $\mathrm{Fe}$ on the surface of the CNTs, which acted as a carbon source for the carbide forming reaction. Although the carbide forming reaction of $\mathrm{Si}$ is not very favorable, the presence of the Fe catalyst facilitated the reaction to form $\mathrm{SiC}$ by acting as nucleation sites. The catalyst mechanism of Fe is widely understood in Vapor-Liquid-Solid (VLS) process, which is used in our experiment. In short, VLS process can be described as precursor from vapor phase preferentially adsorb on and dissolve into the metal droplet and then transport across the droplet to eventually precipitate to form the solid nanostructure. Since catalyst alloys are formed during the process, the growth of the $\mathrm{SiC}$ nanostructures most likely follows the widely accepted VLS or VSS mechanism for the growth of various $1 \mathrm{D}$ nanostructures ${ }^{35-37}$. Because CNTs were present as the carbon source for the carbide forming reaction, $\mathrm{SiC}$ grew on the CNT template, forming the $\mathrm{SiC}$ nanotube structure as the result of the template growth process ${ }^{38}$. The sequence of chemical reactions between $\mathrm{Si}$ and carbon to form the CNT-templated $\mathrm{SiC}$ is as follows:

$$
\begin{aligned}
& \mathrm{SiO}(\mathrm{g})+2 \mathrm{C}(\mathrm{s}) \rightarrow \mathrm{SiC}(\mathrm{s})+\mathrm{CO}(\mathrm{g}) \\
& \mathrm{SiO}(\mathrm{g})+\mathrm{CO}(\mathrm{g}) \rightarrow \mathrm{SiC}(\mathrm{s})+\mathrm{CO}_{2}(\mathrm{~g})
\end{aligned}
$$

Equation (1) indicates that a constant flow of Ar would induce the evolution of SiO gas as a result of the reaction between $\mathrm{Si}$ and $\mathrm{SiO}_{2}$. This $\mathrm{SiO}$ gas then reacts with carbon in the CNTs or carbon monoxide from thermally decomposed CNTs to form $\mathrm{SiC}^{36}$. As discussed above, Fe nanoparticles decorated on the surface of the CNTs facilitated the chemical reaction between $\mathrm{SiO}$ gas and carbon. Through this reaction, SiC grew from the CNT template, while excess carbon dioxide was carried away by the Ar flow.

Figure 2a presents the microstructure corresponding to the $\mathrm{Fe}-\mathrm{CNT} / \mathrm{SiO}_{2}$ schematically shown in Fig. 1d; $\mathrm{Si}$ particles and $\mathrm{SiO}_{2}$ particles mixed with $\mathrm{Fe}-\mathrm{CNTs}$ during sonication to form the dispersion of Fe-CNTs. Although the $\mathrm{Si}$ and $\mathrm{SiO}_{2}$ particles were much larger than Fe-CNT particles, the continuous flow of Ar drove the evolution of $\mathrm{SiO}$ gas from the mixture. Figure $2 \mathrm{~b}$ presents the microstructure of the CNT-templated $\mathrm{SiC}$ nanotubes. Reaction of CNTs with the $\mathrm{Si} / \mathrm{SiO}_{2}$ that provided the $\mathrm{SiO}$ gas transformed the CNTs into $\mathrm{SiC}$ nanotubes. The low-magnification SEM image in Fig. 2b shows large-scale nanowires densely stacked on the substrate, which is an essential feature for future nanodevice applications. The nanotubes have a relatively uniform diameter of ca. $30-40 \mathrm{~nm}$. The XRD patterns of the $\mathrm{CNTs}, \mathrm{Fe}-\mathrm{CNTs} / \mathrm{Si} / \mathrm{SiO}_{2}$ powder mixture, and CNT-templated $\mathrm{SiC}$ nanotubes were used to determine the chemical composition and nature of the synthesized SiC nanotubes (Fig. 2c). The 

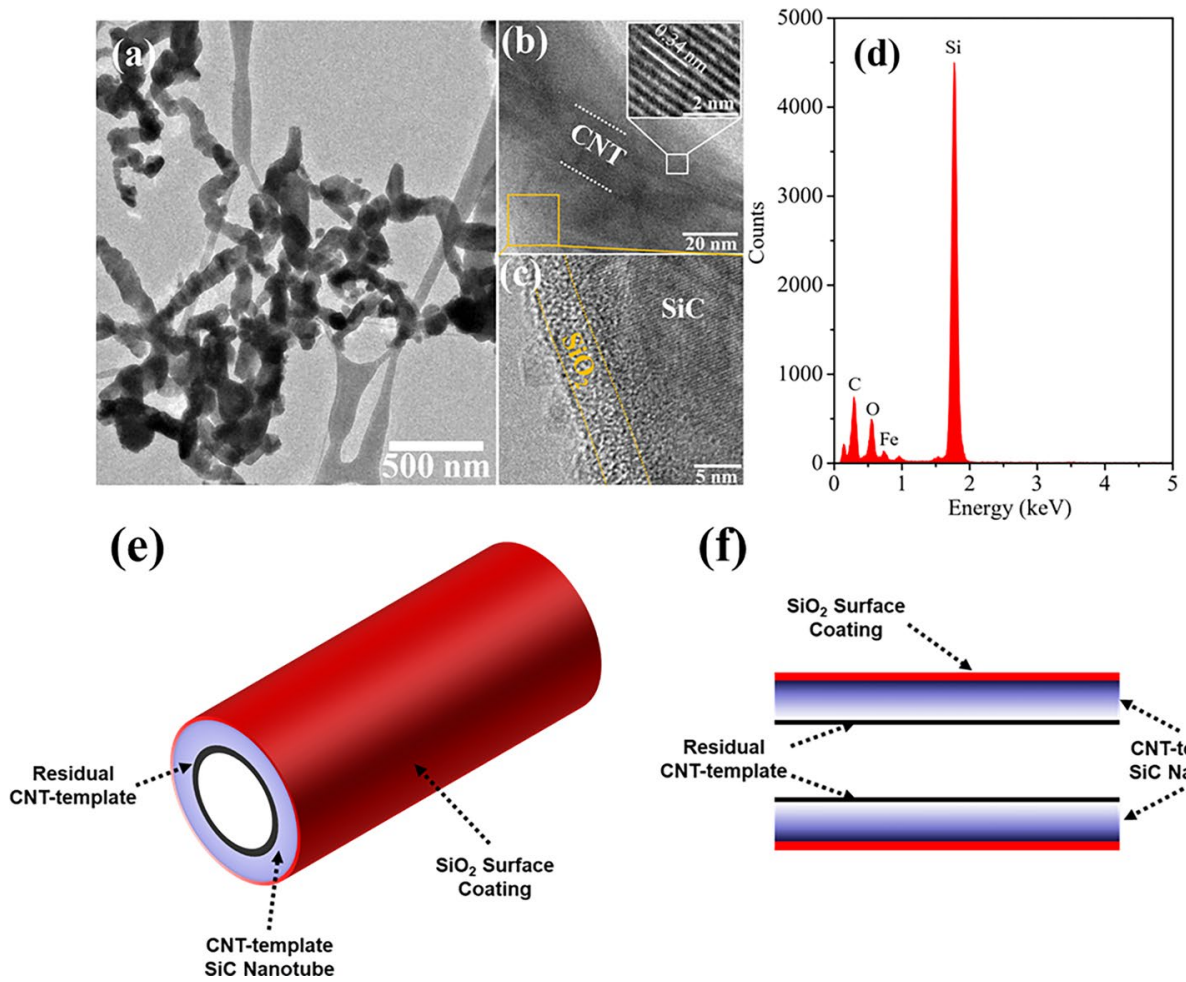

(f)

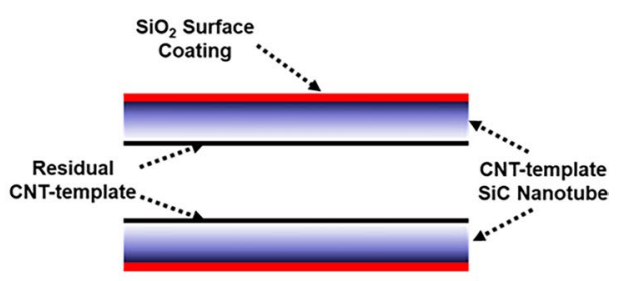

Figure 3. Transmission electron microscopy (TEM) images of (a) CNT-templated SiC nanotubes, (b) CNT inner core, and (c) $\mathrm{SiC}-\mathrm{SiO}_{2}$ interface. (d) Energy-dispersive X-ray spectra, (e) schematic illustrations of the layered structure, (f) cross-section of a SiC@CNT coaxial nanotube.

XRD pattern of the CNTs contains peaks corresponding to those of the carbon structure, as expected from the chemical nature of the CNTs ${ }^{26,39}$. However, when the CNTs were decorated with $\mathrm{Fe}_{2} \mathrm{O}_{3}$ nanoparticles and mixed with $\mathrm{SiO}_{2}$ and $\mathrm{Si}$ particles to form the powder mixture, the peaks for $\mathrm{Fe}_{2} \mathrm{O}_{3}, \mathrm{SiO}_{2}$, and $\mathrm{Si}$ evolved and dominated the XRD pattern. Here, the $\mathrm{SiO}_{2}$ peaks of SiC@CNTs and $\mathrm{Fe}-\mathrm{CNTs} / \mathrm{Si} / \mathrm{SiO} 2$ are matched to cristobalite (PDF \#39-1425) and quartz (PDF \#46-1045), respectively. Nevertheless, weak carbon peaks remained at this stage, consistent with CNTs present as the substrate of the $\mathrm{Fe}_{2} \mathrm{O}_{3}$ nanoparticles. At the completion of the reaction, new peaks for $\mathrm{SiC}$ were evident while those of $\mathrm{Fe}_{2} \mathrm{O}_{3}$ and carbon were mostly absent, which is consistent with the growth of $\mathrm{SiC}$ nanotubes from the CNT template. The Raman spectra of the CNT-templated SiC NTs were used to confirm the presence of residual CNTs in the resulting CNT-templated SiC nanotubes. Figure 2d shows distinctive transverse optical (TO) and longitudinal optical (LO) peaks in the $800-1,000 \mathrm{~cm}^{-1}$ region, suggesting that carbon from the CNTs reacted with $\mathrm{SiO}$ to form $\mathrm{SiC}$ nanotubes ${ }^{40}$. Furthermore, the Raman spectra of the $\mathrm{SiC}$ nanotubes revealed that the CNTs were not completely decomposed and reacted with $\mathrm{Si}$ instead. The presence of distinctive D and G peaks of CNTs confirmed that the CNT-template remained within the SiC nanotubes.

High-resolution TEM was used to characterize the microstructure of the SiC nanotubes. Figure 3a shows how the $\mathrm{SiC}$ nanotubes were densely stacked on the TEM grid. Figure 3b presents a micrograph of a single SiC@CNT nanotube. The two parallel white dotted lines indicate the inner nanotube. The lattice plane spacing of the inner core of about $0.34 \mathrm{~nm}$ is attributed to the (002) planes of the MWCNTs. This confirmed the presence of residual ca. 20-nm diameter MWCNTs as the inner core of the SiC nanotubes. The outer layer of the nanotube consisted of SiCs. The lattice plane spacing of $0.25 \mathrm{~nm}$ corresponds to the SiC (111) crystal plane. The diameter of the outer $\mathrm{SiC}$ layer was ca. $35 \mathrm{~nm}$; this layer was deposited on top of the CNT inner core. An additional ca. 5-nm-thick $\mathrm{SiO}_{2}$ layer was present on the outermost surface of the nanotube (Fig. 3c), in accord with the proposed process, which is in agreement with previously reported results on $\mathrm{SiC}$ material ${ }^{41,42}$. Energy-dispersive X-ray spectroscopy revealed that the material was composed of $\mathrm{C}, \mathrm{O}$, and $\mathrm{Si}$, consistent with $\mathrm{SiO}_{2}, \mathrm{SiC}$, and the CNT core (Fig. 3d). A small amount of Fe was also detected, which corresponds to unreacted Fe on the surface of the CNT core. The $\mathrm{SiO}_{2}$ layer on the surface can enhance the interfacial bond strength between the Al6061 matrix and SiC@CNTs. Previous research has established that $\mathrm{SiO}_{2}$ coatings on the surfaces of $\mathrm{SiC}$ particles significantly enhance the wettability between an $\mathrm{Al}$ alloy matrix and $\mathrm{SiC}$ particles, thereby reducing porosity along the interface between the matrix and the particles. The $\mathrm{SiO}_{2}$ surface coating on the SiC@CNTs similarly enhanced the wetting of the Al alloy matrix during the sintering process, which resulted in greater interfacial bonding between the SiC@CNTs and the matrix. $\mathrm{A} \mathrm{SiO}_{2}$ coating can also act as a barrier to restrict direct contact between $\mathrm{SiC}$ and $\mathrm{Al}$, thereby preventing the formation of brittle carbide phases at the interface ${ }^{43}$. Figure $3 \mathrm{e}, \mathrm{f}$ present schematic illustrations of the microstructure of the SiC@CNT coaxial nanotubes, showing the $\mathrm{SiO}_{2}$ surface coating, CNT-templated $\mathrm{SiC}$ nanotube, and residual CNT core. The morphology and compositional analysis indicate that this coaxial 


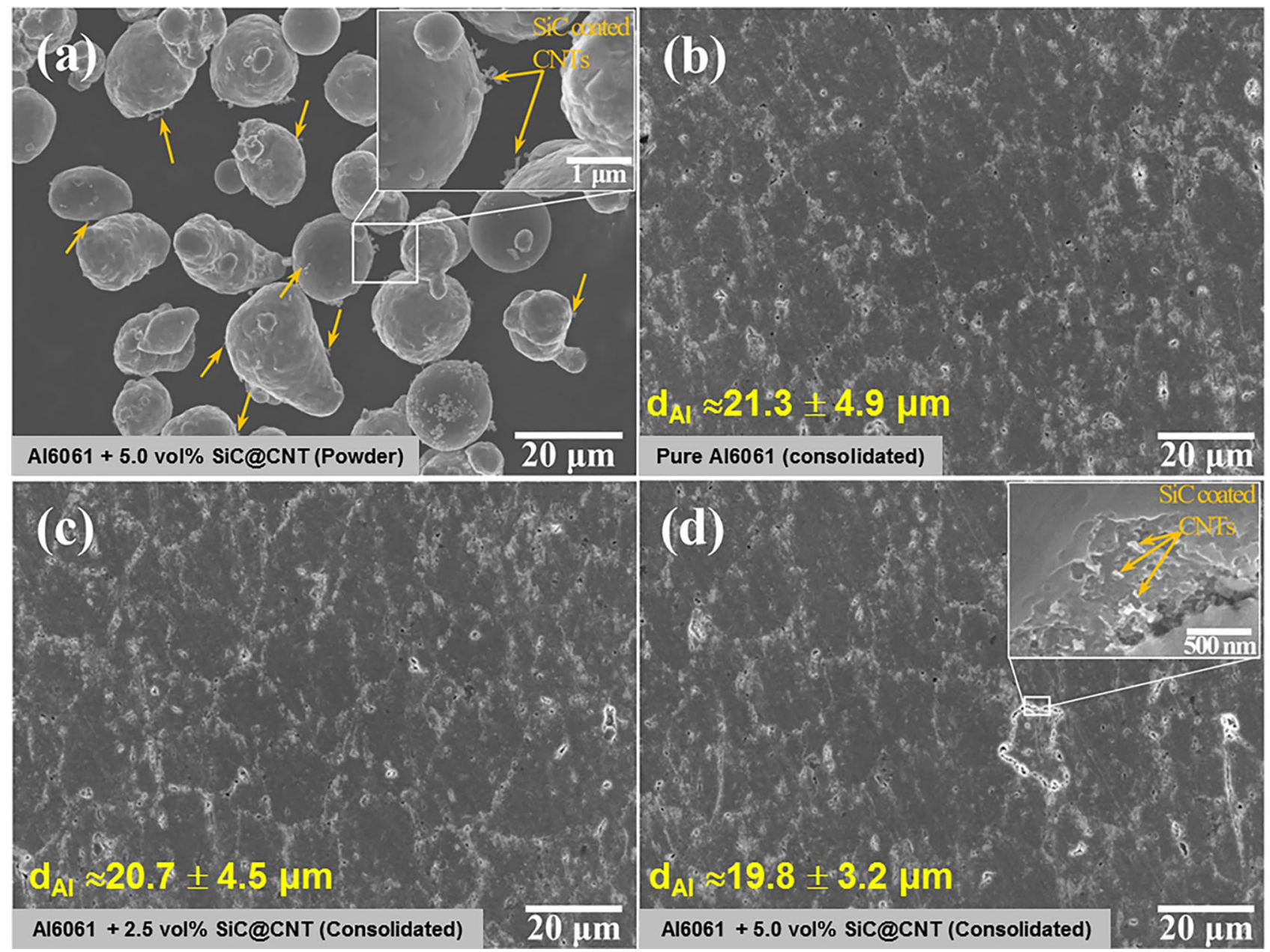

Figure 4. Microstructures and grain sizes of powdered and consolidated samples. (a) Al6061 + 5 vol\% Al6061SiC@CNT powder and consolidated (b) pure Al6061, (c) Al6061 + 2.5 vol\% Al6061-SiC@CNT, and (d) Al6061 + 5 vol\% Al6061-SiC@CNT.

structure resulted from a confined reaction of the carbon nanotubes in which the CNTs served as the template for the continuous growth of SiC nanolayers to form SiC@CNT coaxial nanotubes (Figure S1) ${ }^{23}$.

The $\mathrm{SiC}$ nanotubes were mixed with Al6061 powder using tip sonication and then freeze-dried to obtain a homogenous dispersion of SiC@CNT nanotubes within the Al6061 matrix. The resulting powder mixture was sintered using SPS to complete the fabrication of the Al6061-SiC@CNTs composites. Figure 4a shows the microstructure of the Al6061-SiC@CNTs powder mixture. The Al6061 granules were ca. $15 \mu \mathrm{m}$ in diameter and were coated by SiC@CNTs. When consolidated, the degree of SiC@CNT reinforcement resulted in slight differences in grain sizes. As shown in Fig. 4b, pure Al6061 alloy had an average grain size of $21.3 \mu \mathrm{m}$; the addition of 2.5 and 5.0 vol\% of SiC@CNTs resulted in a reduction of the average grain size to 20.7 (Fig. 4c) and $19.8 \mu \mathrm{m}$ (Fig. 4d), respectively. These size differences were statistically insignificant. The SiC@CNTs were found at the grains and grain boundaries of the consolidated Al6061-SiC@CNT composites (inset of Fig. 4d). SiC@CNTs were observed within the etch pit of Al6061-5.0 vol\% SiC@CNT, suggesting that the SiC@CNTs did not react with the $\mathrm{Al}$ alloy matrix or decompose during the consolidation process. This finding is attributed to the $\mathrm{SiO}_{2}$ coating on the surface of the SiC@CNTs, which acted as a barrier that restricted direct contact between $\mathrm{SiC}$ and $\mathrm{Al}$.

Mechanical properties and mechanical behaviors of SiC@CNT/AI6061 nanocomposites. Figure 5 shows the tensile stress - strain curves of the pure Al6061 and Al6061-SiC@CNT composites. Table 1 lists the Vickers hardness, elastic modulus, yield strength, ultimate tensile strength, and elongation. Strength improved with increasing SiC@CNTs content. Notably, the yield and tensile strengths of the Al6061-5 vol\% SiC@CNT composite were 137.5 and $192.2 \mathrm{MPa}$, respectively, values almost 46\% and 38\% greater than those of pure Al6061. Several strengthening mechanisms can contribute to the mechanical properties of Al6061-SiC@ CNT composites, including solid solution strengthening, grain boundary strengthening, dislocation strengthening by coefficient of thermal expansions (CTE) mismatch, and load-transfer strengthening ${ }^{31}$. The composite matrix contained the same alloy and had similar grain size as pure Al6061, suggesting that solid solution strengthening and grain boundary strengthening did not significantly influence the strength of composites. Dislocations could have formed during rapid cooling in the SPS process due to the large differences between 


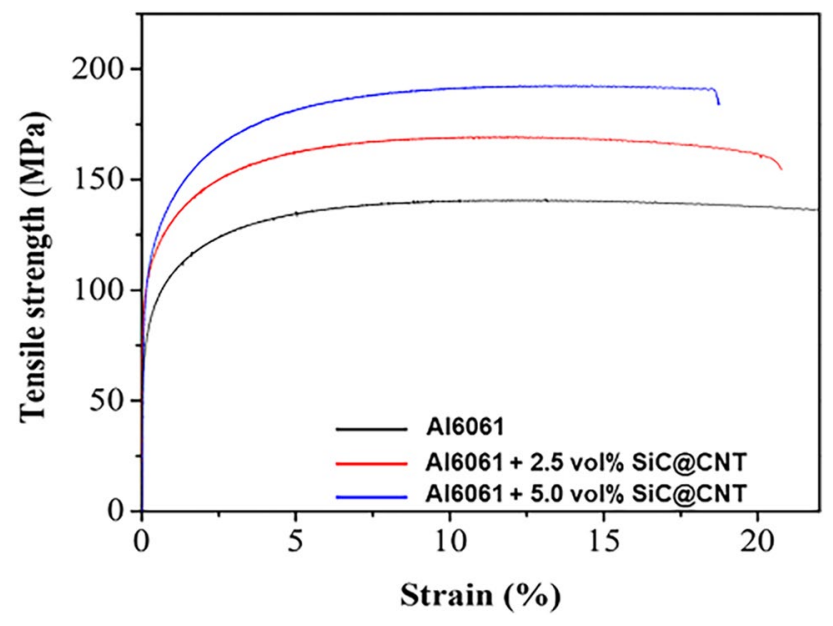

Figure 5. Mechanical properties of the Al6061-SiC@CNT nanocomposites. (a) Stress - strain curves of pure Al6061 and 2.5 vol\% and 5.0 vol\% SiC@CNTs.

\begin{tabular}{|l|l|l|l|l|l|}
\hline Sample & Hardness $\left(\mathbf{H}_{\mathrm{V}}\right)$ & Elastic modulus $(\mathbf{G P a})$ & Yield strength $(\mathbf{M P a})$ & Tensile strength $(\mathbf{M P a})$ & Elongation (\%) \\
\hline Al6061 & 55.1 & 70.2 & 93.9 & 139.2 & 33.5 \\
\hline $\begin{array}{l}\text { Al6061-2.5 vol\% SiC@ } \\
\text { CNT }\end{array}$ & 78.5 & 103.1 & 129.1 & 169.6 & 21.4 \\
\hline $\begin{array}{l}\text { Al6061-5 vol\% SiC@ } \\
\text { CNT }\end{array}$ & 89.6 & 110.8 & 137.5 & 192.2 & 18.1 \\
\hline
\end{tabular}

Table 1. Mechanical properties of Al6061-SiC@CNT nanocomposites.

the CTEs of SiC $\left(4.1 \times 10^{-6} \mathrm{~K}^{-1}\right)^{44}$, CNT $\left(20 \times 10^{-6} \mathrm{~K}^{-1}\right)^{45}$, and $\mathrm{Al}\left(23 \times 10^{-6} \mathrm{~K}^{-1}\right)^{46}$. The enhanced yield strength is attributed to improved load-transfer between the SiC@CNTs reinforcement and the Al matrix. The ultra-thin $\mathrm{SiO}_{2}$ layer contributed to strong interfacial bonding between the reinforcement and matrix, which led to a reduction in the effective load on the matrix by transferring some of the load from the matrix to the reinforcement ${ }^{31}$. Thus, synergistic strengthening by dislocation and load-transfer mainly contributed to the improved strength. This outstanding strengthening efficiency is attributable to the high load-transfer effect induced by the high aspect ratio and enhanced interfacial bonding between the reinforcement and the matrix due to the presence of the thin $\mathrm{SiO}_{2}$ interlayer.

Figure 6 presents the fractography of the pure Al6061 and 5.0 vol\% Al6061-SiC@CNT composite after tensile testing. Dimple fracture morphology, which is a typical fracture mode of ductile materials, occurred in pure Al6061 (Fig. 6a,b). The dimple size was in range of 200-600 nm. In contrast, numerous flat regions were observed in the fracture surface of the composite (Fig. 6c,d). Additionally, SiC@CNT reinforcements (indicated by yellow arrows) were clearly seen, indicating good interfacial bonding between the matrix and the reinforcement. Furthermore, SiC@CNTs displayed a pulled-out morphology, whereby the embedded SiC@CNTs were extruded out toward the fracture surface, consistent with strong bonding of the SiC@CNTs to the Al alloy matrix. Such strong interfacial bonding is attributed to the presence of the $\mathrm{SiO}_{2}$ coating on the SiC@CNTs. Our previous research on surface-oxidized $\mathrm{SiC}_{\mathrm{p}}$-reinforced $\mathrm{Al} 6061$ composites established that the presence of $\mathrm{SiO}_{2}$ on the surface of a reinforcement led to formation of $\mathrm{Al}_{2} \mathrm{O}_{3}$ and $\mathrm{MgAl}_{2} \mathrm{O}_{4}$ phases at the interface, while hindering the formation of $\mathrm{Al}_{4} \mathrm{C}_{3}$. Because $\mathrm{Al}_{4} \mathrm{C}_{3}$ is known to embrittle MMCs, prevention of their formation resulted in enhanced mechanical properties. In this study, we designed the fabrication process to synthesize SiC@CNTs with a $\mathrm{SiO}_{2}$ surface coating to obtain a similar strengthening behavior ${ }^{43}$. Finally, the lower ductility of the composite compared to pure Al6061 is attributed to the increased amount of flat regions ${ }^{47}$. Furthermore, strengthening efficiency $(\mathrm{R})$, defined as:

$$
R=\frac{\sigma_{c}-\sigma_{m}}{\sigma_{m} V_{f}}
$$

where $\sigma_{c}, \sigma_{m}$ is the strength of composites and matrix, respectively, and $V_{f}$ is volume fraction of reinforcement, of the Al6061-SiC@CNT composites was compared with that of other types of SiC reinforcement (Figure S2 in Supporting Information). Surprisingly, the SiC@CNT reinforcement showed the highest strengthening efficiency than the other types of $\mathrm{SiC}$ reinforcements including (nano-)wire and (nano-) particle. Future work will be followed to investigate the origin of the enhanced reinforcing effect of SiC@CNT reinforcement.

Figure 7 presents the friction coefficients and specific wear rates of pure Al6061 and the $2.5 \mathrm{vol} \% \mathrm{SiC} /$ Al6061 and 5.0 vol\% SiC/Al6061 composites. Figure 7a shows that the friction coefficients of the SiC-reinforced 

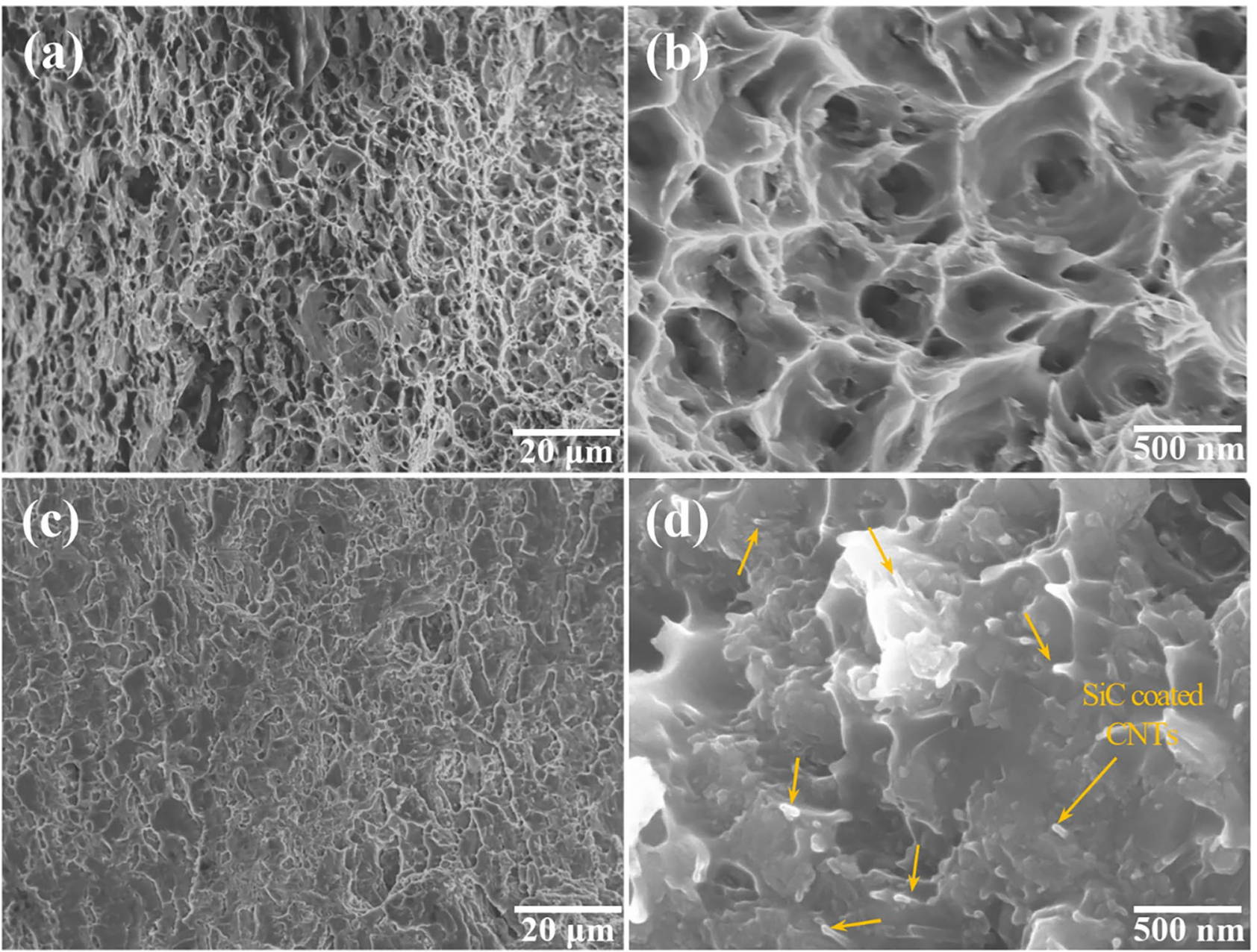

Figure 6. Scanning electron microscopy images of fracture surfaces of pure Al6061 and 5.0 vol\% CNTtemplated Al6061-SiC@CNT nanocomposite. Fracture surfaces of (a, b) pure Al6061 and (c, d) 5.0 vol\% CNTtemplated Al6061-SiC@CNT nanocomposite at different magnifications.
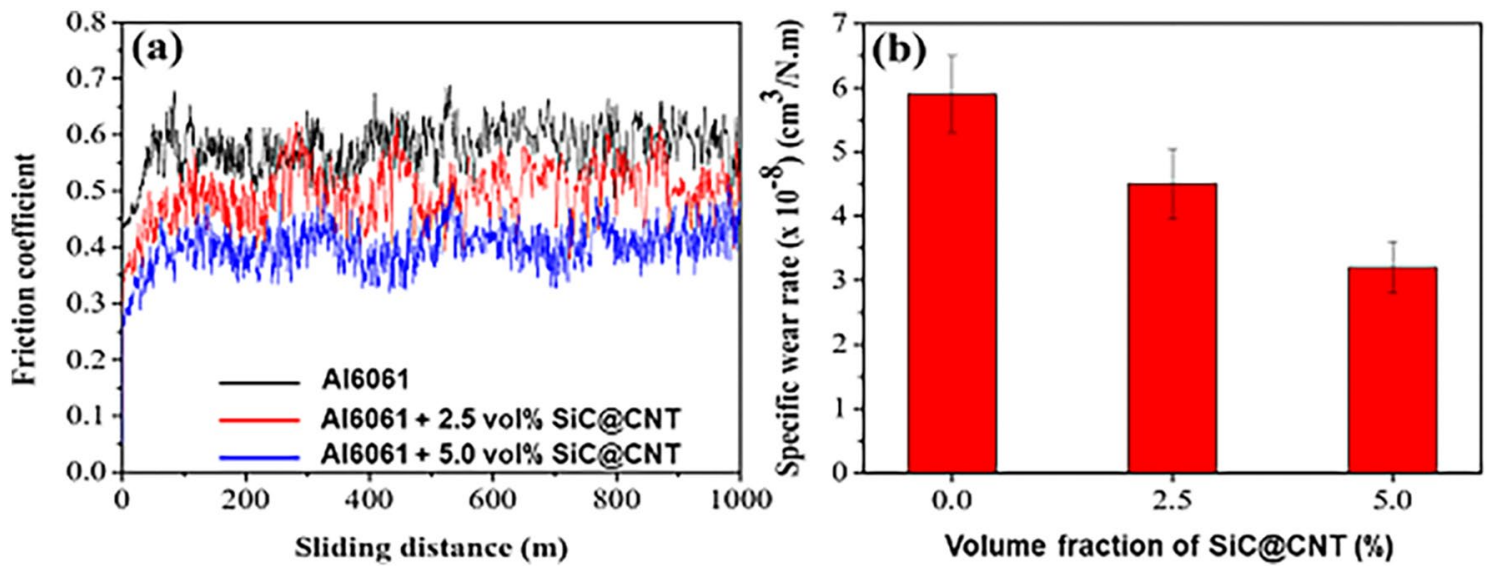

Figure 7. Wear properties of CNT-templated Al6061-SiC@CNT nanocomposites. (a) Friction coefficients and (b) wear rates of Al6061 and 2.5 vol\% and 5.0 vol\% CNT-templated Al6061-SiC@CNT nanocomposites.

composites were lower than that of pure Al6061. The values for pure Al6061, $2.5 \mathrm{vol} \% \mathrm{SiC} / \mathrm{Al} 6061$, and 5.0 vol\% $\mathrm{SiC} / \mathrm{Al} 6061$ were $0.62,0.51$, and 0.43 , respectively. Additionally, higher $\mathrm{SiC}$ content led to reduction in the friction coefficient. A lower friction coefficient reduces the specific wear rate of composites (Fig. 7b). The specific wear rates of pure Al6061, $2.5 \mathrm{vol} \% \mathrm{SiC} / \mathrm{Al} 6061$, and $5.0 \mathrm{vol} \% \mathrm{SiC} / \mathrm{Al} 6061$ were $5.82 \times 10^{-8}, 4.55 \times 10^{-8}$, and $3.21 \times 10^{-8}$ $\mathrm{cm}^{3} / \mathrm{Nm}$, respectively. The lower friction coefficient and specific wear rate of the composites are attributed to their 

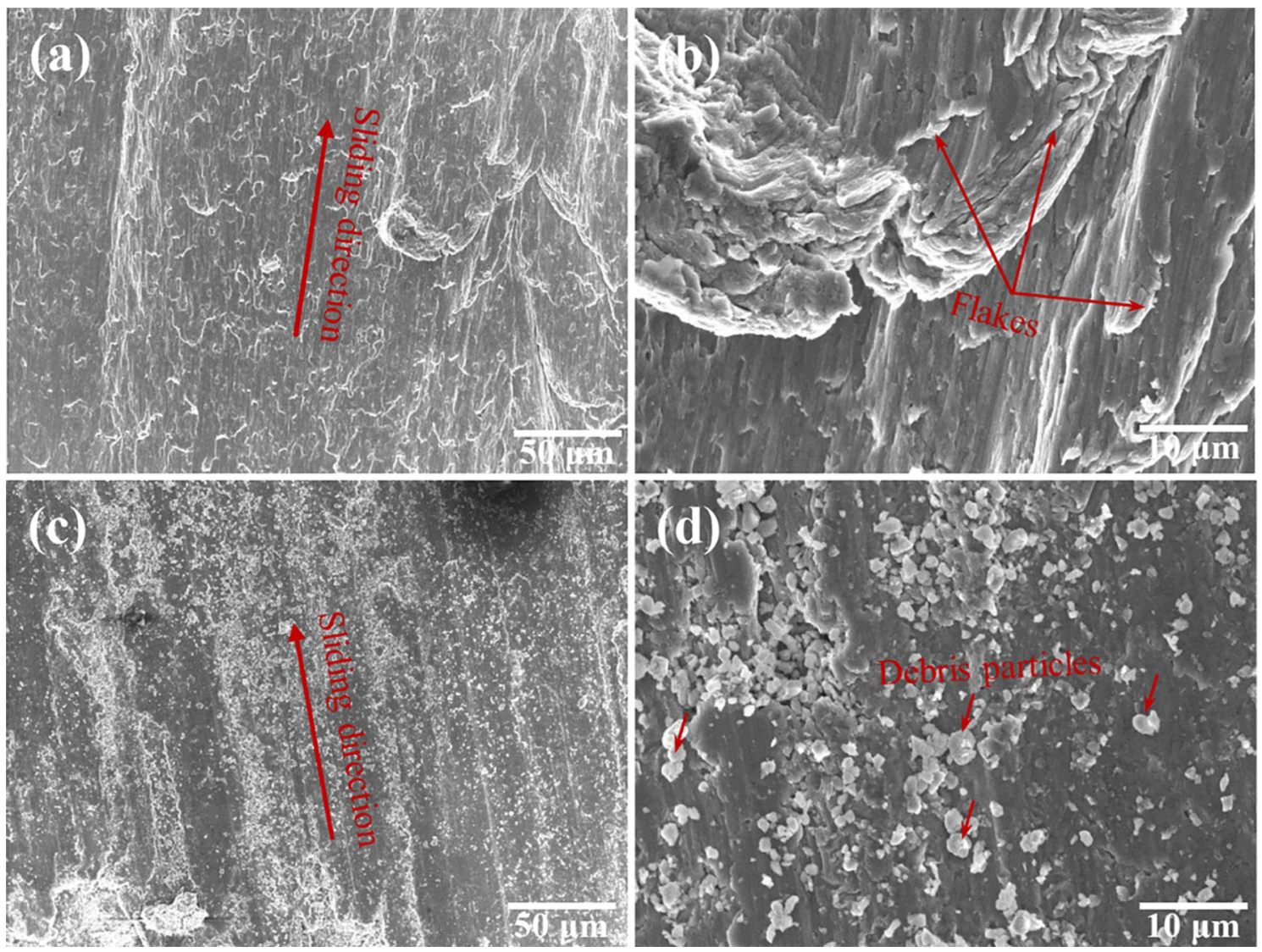

Figure 8. Wear surfaces of (a, b) Al6061 and (c, d) 5.0 vol\% CNT-templated Al6061-SiC@CNT nanocomposites.

higher hardness and strength. Surprisingly, the addition of 5.0 vol\% of $\mathrm{SiC}$ led to a $31 \%$ lower friction coefficient and $45 \%$ lower specific wear rate than pure Al6061. The friction coefficient of $5.0 \mathrm{vol} \% \mathrm{SiC} / \mathrm{Al} 6061$ was much lower than that of the 12.0 vol\% SiC particle-reinforced Al6061 composite ${ }^{48}$, which is attributed to the higher strengthening efficiency of the CNT-templated $\mathrm{SiC}$ nanotubes compared with other types of $\mathrm{SiC}$ reinforcements. The templated $\mathrm{SiC} / \mathrm{Al}$ composite has markedly superior interfacial bond strength between the $\mathrm{SiC}$ and $\mathrm{Al}$ matrix than the other types of $\mathrm{SiC}$ reinforcement.

Wear properties of SiC@CNT/AI6061 nanocomposites. Figure 8 presents the wear surfaces of pure Al6061 (Fig. 8a,b) and the $5.0 \mathrm{vol} \% \mathrm{SiC} / \mathrm{Al} 6061$ composite (Fig. 8c,d). The addition of SiC reinforcement led to obvious differences in the wear surfaces. For pure Al6061, the wear surface was deeply grooved and contained many craters, microholes, and delaminations. A deformation zone was also observed in the wear surface. Large portions of material were removed by periodic delamination fractures during the plastic deformation. The wear surface of the pure Al6061 suggests that the wear mechanism is a combination of abrasive, delamination, and deformation. In the case of the $5.0 \mathrm{vol} \% \mathrm{SiC} / \mathrm{Al} 6061$ composite (Fig. 8c,d), shallow abrasive grooves were formed and debris particles were uniformly dispersed without craters and microholes. Additionally, no delamination or deformation morphology was observed. The wear surface of the composite free of craters, delamination, and deformation explains the improved wear properties. Moreover, wear debris, which is present on the sliding surface and covers the matrix, behaves as hard abrasive particles and limits material loss ${ }^{49,50}$. Therefore, the wear mechanisms of the composite were predominantly abrasive.

\section{Conclusion}

We developed novel SiC@CNT coaxial nanotubes via a CVD method using a silica source and CNTs. The SiC nanostructures were characterized by XRD, SEM, TEM, and Raman spectroscopy. The growth of SiC@CNT nanotubes is attributed to the reaction of $\mathrm{SiO}$ with $\mathrm{CO}$ on CNT surfaces assisted by a Fe catalyst. The $\mathrm{SiC}$ outer layer was continuous and uniform on the CNT template, and the inner CNT core was retained. We used SiC@ CNT as a reinforcement to enhance the mechanical and tribological properties of Al6061 alloy. The Al6061SiC@CNT composite provided significant improvements in terms of mechanical and tribological properties. The yield strength and Young's modulus of Al6061-SiC@CNT were enhanced by 46\% and 58\%, respectively, upon 5 vol\% addition of SiC@CNT. The friction coefficient and specific wear rate of Al6061-SiC@CNT composites were reduced by $31 \%$ and $45 \%$, respectively, due to the wear mechanism transition from a combination of adhesive and severe delamination wear to abrasive wear. The excellent mechanical and tribological properties of Al6061-SiC@ 
CNT composites show promise for structural and wear applications, particularly those subjected to heavy duty conditions, which cannot be attainable with traditional reinforcements.

\section{Experimental}

Materials. Commercial MWCNTs having an average diameter of $15 \mathrm{~nm}$ and a length of $10 \mu \mathrm{m}$ (Hanwha Chemical Co., Ltd., China), and Si powder $(15.5 \mu \mathrm{m})$ and $\mathrm{SiO}_{2}$ powder $(200 \mathrm{~nm})$ (both from Sigma-Aldrich, St. Louis, USA) were used to prepare the SiC-coated CNT nanowires. Lumi M Al6061 powder (diameter: $18.5 \mu \mathrm{m}$ ) was used as the matrix material.

Functionalization of carbon nanotubes. MWCNTs ( $1 \mathrm{~g})$ were first functionalized with carboxyl, hydroxyl, and epoxide groups by acid soaking and sonication in a mixture of $\mathrm{H}_{2} \mathrm{SO}_{4}$ and $\mathrm{HNO}_{3}(3: 1 \mathrm{v} / \mathrm{v})$ at $70{ }^{\circ} \mathrm{C}$ for $5 \mathrm{~h}$. The obtained dispersion was filtered, washed, and then redispersed in distilled water. Tip sonicating for 30 min formed a stable CNT dispersion.

Fabrication of Fe-CNTs and CNT-templated SiC nanotubes. Prepared functionalized CNTs were dispersed and mixed with $\mathrm{Fe}\left(\mathrm{NO}_{3}\right)_{3}$ solution $(1 \mathrm{M})$ for $30 \mathrm{~min}$ at $80{ }^{\circ} \mathrm{C}$ under magnetic stirring, followed by filtering and drying at $180^{\circ} \mathrm{C}$ in vacuum for $24 \mathrm{~h}$ to obtain the Fe-coated CNT (Fe-CNT) powder. The appropriate amount of Fe-CNT powder was mixed with $\mathrm{Si}(0.5 \mathrm{~g})$ and $\mathrm{SiO}_{2}(0.5 \mathrm{~g})$ powders in distilled water, followed by tip sonication to obtain the precursor material mixture. The prepared precursor material was heat-treated at $1,400{ }^{\circ} \mathrm{C}$ for $2 \mathrm{~h}$ under an Ar atmosphere to induce formation of SiC on the CNT-template (SiC@CNT).

Fabrication of Al6061-SiC@CNT. Commercially available Al6061 powder was mixed with SiC@CNT in ethanol with pulse ultrasonication ( $5 \mathrm{~s}$ on, $5 \mathrm{~s}$ off pulse) to fabricate $2.5 \mathrm{vol} \%$ and 5 vol\% Al6061-SiC@CNT nanocomposites. Ultrasonication was maintained for $30 \mathrm{~min}$ to ensure a homogenous dispersion. The vessel containing the Al6061-SiC@CNT suspension was immediately immersed in liquid $\mathrm{N}_{2}$ for 3 min, followed by freeze-drying (Freeze Dryer; ilShin Biobase, South Korea) at $-68^{\circ} \mathrm{C}$ for $48 \mathrm{~h}$ in vacuum ( $14 \mathrm{mTorr}$ ). Finally, the obtained composite powder was formed into cylinders having dimensions of $20 \mathrm{~mm}$ diameter $\times 4 \mathrm{~mm}$ length using SPS (Dr. Sinter Lab Series) at $50 \mathrm{MPa}$ and $560^{\circ} \mathrm{C}$ for $5 \mathrm{~min}$ in a vacuum. Pure Al6061 (i.e., without SiC@ $\mathrm{CNT}$ ) was also prepared under the same conditions for comparison.

Characterization of the Al6061-SiC@CNT nanocomposites. Microstructures of SiC@CNT and Al6061-SiC@CNT nanocomposites were characterized using field-emission scanning electron microscopy (FE-SEM; S-4800; Hitachi, Japan) at an accelerating voltage of 5-10 kV and transmission electron microscopy (TEM; JEM-ARM200F; JEOL, Japan) at an accelerating voltage of $300 \mathrm{kV}$. X-ray diffraction (XRD) patterns were obtained using a D/MAX-2500 instrument (Rigaku, Japan). The chemical nature of SiC@CNTs was characterized using a dispersive Raman spectrometer (ARAMIS; Horiba Jobin Yvon, France).

Mechanical testing. Tensile strengths of nanocomposites were evaluated by a microforce testing system (Instron 8848; Instron, USA). The mechanical test was conducted according to our previous testing protocol ${ }^{43}$. A specimen was processed into a dog-bone shape having dimensions of $16.5 \times 2.0 \mathrm{~mm}^{2}$ with a 0.75 -mm radius of curvature for mechanical testing according to the standard ASTM E8. A strain rate of $0.2 \mathrm{~mm} / \mathrm{min}$ was applied to each tensile test. Fracture surfaces were analyzed by FE-SEM. Strain during the test was measured precisely by digital image-correlation using ARAMIS software (ARAMIS 5 M; ARAMIS, Germany). The elastic modulus of each sample was determined using the $0.2 \%$ strain offset linear slope method.

Wear testing. Wear properties of the nanocomposites were evaluated by a pin-on-disc machine (RB 102$\mathrm{PD})$. The wear test was conducted according to our previous testing procedures ${ }^{43}$. A polished EN-31 steel disc was used as a counter material for the wear test. The wear test was conducted under a load of $98.1 \mathrm{~N}$, a fixed sliding speed of $200 \mathrm{rpm}$, and a sliding distance of 1,000 m. For comparison, the friction coefficient of each composite materials was calculated from the average friction coefficient of the last $100 \mathrm{~m}$ of the test.

Received: 8 April 2020; Accepted: 26 June 2020

Published online: 30 July 2020

\section{References}

1. Das, D. K., Mishra, P. C., Singh, S. \& Pattanaik, S. Fabrication and heat treatment of ceramic-reinforced aluminium matrix composites-A review. Int. J. Mech. Mater. Eng. 9, 1-15 (2014).

2. Bodunrin, M. O., Alaneme, K. K. \& Chown, L. H. Aluminium matrix hybrid composites: A review of reinforcement philosophies; Mechanical, corrosion and tribological characteristics. J. Mater. Res. Technol. 4, 434-445 (2015).

3. Manigandan, K., Srivatsan, T. S., Ren, Z. \& Zhao, J. Influence of reinforcement content on tensile response and fracture behavior of an aluminum alloy metal matrix composite. Adv. Compos. Aerosp. Mar. L. Appl. II(2013), 103-119 (2016).

4. Davis, J. R. Light metals and alloys-aluminum and aluminum alloys. Alloy. Underst. Basics, https://doi.org/10.1361/autb2001p351 351-416 (2001).

5. Mishra, A. K., Sheokand, R. \& Srivastava, R. K. Tribological behaviour of Al-6061/SiC metal matrix composite by Taguchi's techniques. Int. J. Sci. Res. Publ. 2, 1-8 (2012) 
6. Gupta, M., Lai, M. O. \& Soo, C. Y. Effect of type of processing on the micro structural features and mechanical properties of Al-Cu/ $\mathrm{SiC}$ metal matrix composites. Mater. Sci. Eng. A 210, 114-122 (1996).

7. Barmouz, M., Besharati Givi, M. K. \& Seyfi, J. On the role of processing parameters in producing $\mathrm{Cu} / \mathrm{SiC}$ metal matrix composites via friction stir processing: Investigating microstructure, microhardness, wear and tensile behavior. Mater. Charact. 62, 108-117 (2011).

8. Akramifard, H. R., Shamanian, M., Sabbaghian, M. \& Esmailzadeh, M. Microstructure and mechanical properties of Cu/SiC metal matrix composite fabricated via friction stir processing. Mater. Des. 54, 838-844 (2014).

9. Prasad Reddy, A., Vamsi Krishna, P., Narasimha Rao, R. \& Murthy, N. V. Silicon carbide reinforced aluminium metal matrix nano composites-A review. Mater. Today Proc. 4, 3959-3971 (2017).

10. Wu, Y., Kim, G. Y., Anderson, I. E. \& Lograsso, T. A. Fabrication of A16061 composite with high SiC particle loading by semi-solid powder processing. Acta Mater. 58, 4398-4405 (2010).

11. Swamy, N. R. P., Ramesh, C. S. \& Chandrashekar, T. Effect of heat treatment on strength and abrasive wear behaviour of Al6061SiCp composites. Bull. Mater. Sci. 33, 49-54 (2010).

12. Veeresh Kumar, G. B., Rao, C. S. P. \& Selvaraj, N. Studies on mechanical and dry sliding wear of Al6061-SiC composites. Compos. Part B Eng. 43, 1185-1191 (2012).

13. Parvin, N., Assadifard, R., Safarzadeh, P., Sheibani, S. \& Marashi, P. Preparation and mechanical properties of SiC-reinforced Al6061 composite by mechanical alloying. Mater. Sci. Eng. A 492, 134-140 (2008).

14. Umanath, K., Palanikumar, K. \& Selvamani, S. T. Analysis of dry sliding wear behaviour of $\mathrm{Al} 6061 / \mathrm{SiC} / \mathrm{Al}_{2} \mathrm{O}_{3}$ hybrid metal matrix composites. Compos. Part B Eng. 53, 159-168 (2013).

15. Reihani, S. M. S. Processing of squeeze cast Al6061-30vol\% SiC composites and their characterization. Mater. Des. 27, 216-222 (2006).

16. Yu, S. Y., Ishii, H., Tohgo, K. \& Young Tae Cho, D. D. Temperature dependence of sliding wear behavior in SiC whisker or SiC particulate reinforced 6061 aluminum alloy composite. Wear 213, 21-28 (1997).

17. Liang, Y. N., Ma, Z. Y., Li, S. Z., Li, S. \& Bi, J. Effect of particle size on wear behaviour of SiC particulate-reinforced aluminum alloy composites. J. Mater. Sci. Lett. 14, 114-116 (1995).

18. Wang, X. Y. et al. One-step synthesis of orientation accumulation SiC-C coaxial nanocables at low temperature. J. Mater. Chem. 19, 2958-2962 (2009).

19. Niu, J. J. \& Wang, J. N. A simple route to synthesize scales of aligned single-crystalline $\mathrm{SiC}$ nanowires arrays with very small diameter and optical properties. J. Phys. Chem. B 111, 4368-4373 (2007).

20. Guo, S., Dong, S. \& Wang, E. Constructing carbon-nanotube/metal hybrid nanostructures using homogeneous $\mathrm{TiO} 2$ as a spacer. Small 4, 1133-1138 (2008).

21. Carny, O., Shalev, D. E. \& Gazit, E. Fabrication of coaxial metal nanocables using a self-assembled peptide nanotube scaffold. Nano Lett. 6, 1594-1597 (2006).

22. Ku, J. R., Vidu, R., Talroze, R. \& Stroeve, P. Fabrication of nanocables by electrochemical deposition inside metal nanotubes. J. Am. Chem. Soc. 126, 15022-15023 (2004).

23. Qi, X. et al. Preparation and characterization of SiC@CNT coaxial nanocables using CNTs as a template. CrystEngComm 16, 9697-9703 (2014).

24. Guo, S. et al. Carbon nanotube/silica coaxial nanocable as a three-dimensional support for loading diverse ultra-high-density metal nanostructures: Facile preparation and use as enhanced materials for electrochemical devices and SERS. Chem. Mater. 21, 2247-2257 (2009).

25. Chen, G., Wang, Z. \& Xia, D. One-pot synthesis of carbon nanotube@SnO2-Au coaxial nanocable for lithium-ion batteries with high rate capability. Chem. Mater. 20, 6951-6956 (2008).

26. Pan, Y., Zhu, P., Wang, X. \& Li, S. Preparation and characterization of one-dimensional SiC-CNT composite nanotubes. Diam. Relat. Mater. 20, 310-313 (2011).

27. Saito, T., Matsushige, K. \& Tanaka, K. Chemical treatment and modification of multi-walled carbon nanotubes. Phys. B Condens. Matter 323, 280-283 (2002).

28. Fang, Z. et al. Efficient synergy of photocatalysis and adsorption of hexavalent chromium and rhodamine B over Al4SiC4/rGO hybrid photocatalyst under visible-light irradiation. Appl. Catal. B Environ. 241, 548-560 (2019).

29. Cha, S. I., Kim, K. T., Arshad, S. N., Mo, C. B. \& Hong, S. H. Extraordinary strengthening effect of carbon nanotubes in metalmatrix nanocomposites processed by molecular-level mixing. Adv. Mater. 17, 1377-1381 (2005).

30. Hwang, J. et al. Enhanced mechanical properties of graphene/copper nanocomposites using a molecular-level mixing process. Adv. Mater. 25, 6724-6729 (2013).

31. Yoo, S. C., Lee, J. \& Hong, S. H. Synergistic outstanding strengthening behavior of graphene/copper nanocomposites. Compos. Part B Eng. 176 (2019).

32. Xiao, F. et al. Growth of metal-metal oxide nanostructures on freestanding graphene paper for flexible biosensors. Adv. Funct. Mater. 22, 2487-2494 (2012).

33. Song, S., Rao, R., Yang, H., Liu, H. \& Zhang, A. Facile synthesis of $\mathrm{Fe}_{3} \mathrm{O}_{4} / \mathrm{MWCNTs}$ by spontaneous redox and their catalytic performance. Nanotechnology 21 (2010).

34. Qian, W., Chen, J., Wu, L., Cao, F. \& Chen, Q. Synthesis of polygonized carbon nanotubes utilizing inhomogeneous catalyst activity of nonspherical Fe3O4 nanoparticles. J. Phys. Chem. B 110, 16404-16407 (2006).

35. Kuznetsov, V. L., Usoltseva, A. N. \& Mazov, I. N. Common features of the formation mechanism of carbon filaments, nanotubes, and silicon carbide whiskers on metal catalysts. Fullerenes Nanotub. Carbon Nanostruct. 13, 121-129 (2005).

36. Sun, X. H. et al. Formation of silicon carbide nanotubes and nanowires via reaction of silicon (from disproportionation of silicon monoxide) with carbon nanotubes. J. Am. Chem. Soc. 124, 14464-14471 (2002).

37. Zhang, L., Zhuang, H., Jia, C. L. \& Jiang, X. Role of catalyst in controlling the growth and morphology of one-dimensional SiC nanostructures. CrystEngComm 17, 7070-7078 (2015).

38. Nhut, J. M. et al. Synthesis and catalytic uses of carbon and silicon carbide nanostructures. Catal. Today 76, 11-32 (2002).

39. Morisada, Y., Miyamoto, Y., Takaura, Y., Hirota, K. \& Tamari, N. Mechanical properties of SiC composites incorporating SiC-coated multi-walled carbon nanotubes. Int. J. Refract. Met. Hard Mater. 25, 322-327 (2007).

40. Bechelany, M., Brioude, A., Cornu, D., Ferro, G. \& Miele, P. A Raman spectroscopy study of individual SiC nanowires. Adv. Funct. Mater. 17, 939-943 (2007).

41. Liu, W., Chen, J., Chou, K. C. \& Hou, X. Large scale fabrication of dumbbell-shaped biomimetic SiC/SiO2 fibers. CrystEngComm 17, 9318-9322 (2015).

42. Liu, W., Chen, J., Yang, T., Chou, K. C. \& Hou, X. Enhancing photoluminescence properties of $\mathrm{SiC} / \mathrm{SiO} 2$ coaxial nanocables by making oxygen vacancies. Dalt. Trans. 45, 13503-13508 (2016).

43. Van Trinh, P., Lee, J., Minh, P. N., Phuong, D. D. \& Hong, S. H. Effect of oxidation of SiC particles on mechanical properties and wear behavior of SiCp/Al6061 composites. J. Alloys Compd. 769, 282-292 (2018).

44. Nelson, W. E., Halden, F. A. \& Rosengreen, A. Growth and properties of $\beta$-SiC single crystals. J. Appl. Phys. 37, 333-336 (1966).

45. Deng, L. et al. Coefficient of thermal expansion of carbon nanotubes measured by Raman spectroscopy. Appl. Phys. Lett. 104 (2014). 
46. Ci, L., Ryu, Z., Jin-Phillipp, N. Y. \& Rühle, M. Investigation of the interfacial reaction between multi-walled carbon nanotubes and aluminum. Acta Mater. 54, 5367-5375 (2006).

47. Wu, Y., Kim, G. Y. \& Russell, A. M. Effects of mechanical alloying on an Al6061-CNT composite fabricated by semi-solid powder processing. Mater. Sci. Eng. A 538, 164-172 (2012).

48. Halil, K., Ismail, O., Sibel, D. \& Ramazan, Ç. Wear and mechanical properties of Al6061/SiC/B4C hybrid composites produced with powder metallurgy. J. Mater. Res. Technol. 8, 5348-5361 (2019).

49. Prashanth, K. G. et al. Processing of Al-12Si-TNM composites by selective laser melting and evaluation of compressive and wear properties. J. Mater. Res. 31, 55-65 (2016).

50. Prashanth, K. G. \& Murty, B. S. Production, kinetic study and properties of Fe-based glass and its composites. Mater. Manuf. Process. 25, 592-597 (2010).

\section{Acknowledgements}

This work was supported by the Industrial Technology Innovation Program (10076438, Development of Metal Matrix Composites with high stiffness and lightweight and Applications of Piston pin and Brake-disc) funded By the Ministry of Trade, Industry \& Energy (MOTIE, Korea). The author (PVT) gratefully acknowledges the National Research Foundation of Korea (NRF) for the financial support under postdoctoral fellowship program.

\section{Author contributions}

S.C.Y.: Conceptualization of original research, Investigation and experiment, Writing-Original manuscript text, prepared Figures 1-4, prepared tables/B.K.: Conceptualization of original research, Investigation and experiment, Writing-Original manuscript text, prepared Figures 5-8/P.V.T.: Investigation and experiment, Visualization/ D.D.P.: Project administration/S.H.H.: Conceptualization of original research and project, Writing-Review \& Editing, Supervision.

\section{Competing interests}

The authors declare no competing interests.

\section{Additional information}

Supplementary information is available for this paper at https://doi.org/10.1038/s41598-020-69341-z.

Correspondence and requests for materials should be addressed to S.H.H.

Reprints and permissions information is available at www.nature.com/reprints.

Publisher's note Springer Nature remains neutral with regard to jurisdictional claims in published maps and institutional affiliations.

(c) (i) Open Access This article is licensed under a Creative Commons Attribution 4.0 International License, which permits use, sharing, adaptation, distribution and reproduction in any medium or format, as long as you give appropriate credit to the original author(s) and the source, provide a link to the Creative Commons license, and indicate if changes were made. The images or other third party material in this article are included in the article's Creative Commons license, unless indicated otherwise in a credit line to the material. If material is not included in the article's Creative Commons license and your intended use is not permitted by statutory regulation or exceeds the permitted use, you will need to obtain permission directly from the copyright holder. To view a copy of this license, visit http://creativecommons.org/licenses/by/4.0/.

(C) The Author(s) 2020 